\title{
Research in Family Medicine in Developing Countries
}

\author{
Bruce L. W. Sparks, MBBCh \\ (Witwatersrand), MFGP(SA), MRCGP, \\ FRCGP $P^{1,2}$
}

Shatendra K. Gupta, MBBS,

$\mathrm{MD}(\mathrm{GP})^{3,4}$

'World Organization of Family Doctors (Wonca)

${ }^{2}$ Department of Family Medicine, University of the Witwatersrand, Johannesburg, South Africa

${ }^{3}$ Wonca Middle East and South East Asia Region (MESAR)

${ }^{4}$ Tribhuvan University, Institute of Medicine, Kathmandu, Nepal

Conflicts of interest: none reported

\section{CORRESPONDING AUTHOR}

Bruce Sparks, MBBCh

Department of Family Medicine

Faculty of Health Sciences

York Road

Parktown, 2193

South Africa

brucespa@global.co.za

\begin{abstract}
The output of family medicine research in developing countries varies vastly from country to country and also within countries. Most research originates from academic departments of family medicine or from collaborative initiatives with researchers in developed countries. There is generally a paucity of researchers, resources, and expertise. Many factors affecting the research output in primary care internationally applies in developing countries, but there are also factors that are unique to these countries. Solutions require financial resources and international goodwill. Wonca could play a major role in enhancing research in family medicine in the developing world.
\end{abstract}

Ann Fam Med 2004;2(Suppl 2):S55-S59. DOI: 10.1370/afm.192.

\section{INTRODUCTION}

$\mathrm{T}$ The nature and content of the practice of primary care generalists in the developing world varies considerably. Family medicine (which includes family practice and general practice), as a relatively recently defined discipline, does not exist in many developing countries, where the term family medicine may not even be known within the medical fraternity. In most developing countries, especially in Africa, there are no academic departments of family medicine, and in some there are no family practitioners as we would know them in the more developed world. Instead, there are primary care physicians working in community clinics or hospitals who may be responsible for the total care of patients, including public health aspects. In some developing nations there may be dual systems of state-employed primary care physicians and private family practitioners caring for sectors of the population on a fee-for-service basis. Where academic departments of family medicine offering postgraduate training exist, they may or may not include a research component in their training programs. In some countries, such as Korea, South Africa, Nigeria, Philippines, Nepal, and Sri Lanka, physicians must complete a research project and report as a component of family medicine training through universities or colleges before registration or board certification. In others, such as Fiji, Croatia, the Caribbean, and Indonesia, steps have been taken by associations of family physicians to encourage practicebased research as a component of continuing professional development. ${ }^{1}$

Some developing countries have centers of academic research excellence equal to the best in the developed world, although to define generic family medicine research in developing countries is difficult. Family physicians are also often involved in exploring the larger community issues, such as strategies for health delivery and ways to address the major burdens of disease in the community. They themselves may not even consider such activities to be family medicine endeavors. In addition, topics of relevance to family doctors in these countries may sometimes not be found in family medicine journals. For instance research conducted by family practitioners in rural areas on the use of mosquito nets in managing childhood malaria 


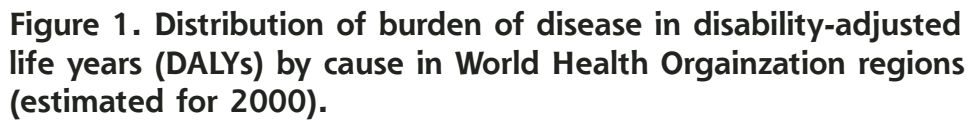

Figure 1. Distribution of burden of disease in disability-adjusted life years (DALYs) by cause in World Health Orgainzation regions (estimated for 2000).

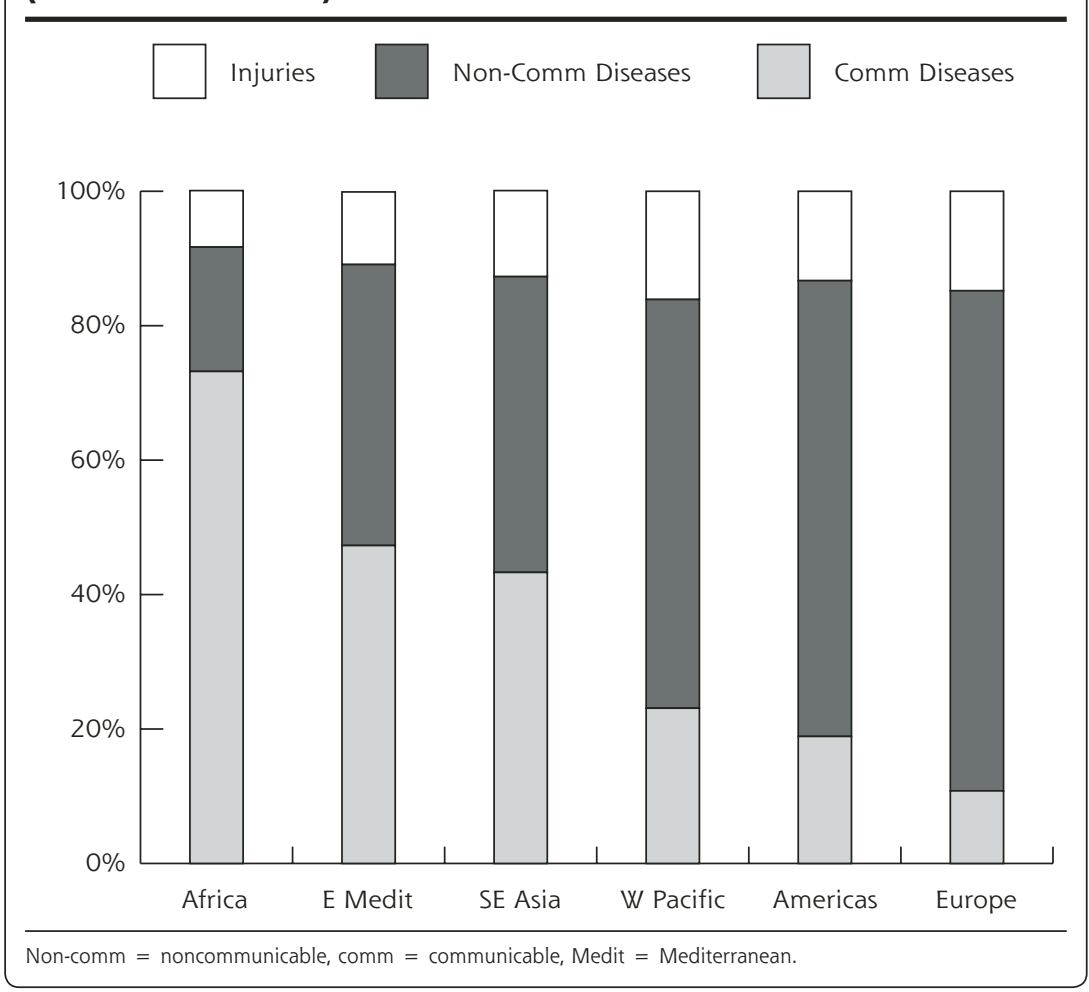

tive, efficient, and responsive to local needs and the issues of daily practice. To achieve such health care demands an appropriate evidence-based approach to design strategies that work. Regrettably, research conducted in the developed world may not be applicable to local circumstances, conditions, and resources. ${ }^{2,3}$ Analysis of the burden of disease in less developed areas of the world shows that communicable diseases are the major contributor to the burden (Figure 1). ${ }^{4}$ Many of these conditions are preventable, and ideally the scope of research should be focused on this illness category. Few relevant, burdenbased clinical trials, however, are done in sub-Saharan Africa. ${ }^{5,6}$

A survey of physicians in secondary and tertiary hospitals in developing countries indicates that overall, local research and publications were most likely to effect change in clinical practice, after which were international then would probably be accepted for publication in a public health journal, and work on the impact of concepts of masculinity on rape, a highly relevant topic for primary care physicians, would probably be considered social science research by most publications in the developed countries. Excellent research within the discipline, however, has been produced in less developed regions, mainly by those who are associated in some way with academic departments, research institutes, or international collaborative groups. A similar situation probably exists in more developed regions.

This article does not reflect so much on the positive aspects of family medicine research in the developing world $_{i}$ instead, it focuses mainly on the constraints to research output drawn from our particular experience and from the general medical literature.

\section{THE NEED FOR MORE RESEARCH IN DEVELOPING COUNTRIES}

Research may not be an integral part of the daily work of a family physician, even in the developed world, but every physician should be able to apply evidence appropriately in clinical practice. Financial resources for health care are limited in developing countries, so it is vital that the health care delivery is cost-effec- regional publications, respectively. ${ }^{7}$ This finding emphasizes that conducting high-quality local research is probably the most effective way of getting research findings into practice in developing countries. The same could probably apply in primary care as well, provided that the findings are relevant and locally applicable. Family physicians, however, also require critical reading skills to be able to consider the value of those relevant reports not yet subject to systematic review.

"Although 90\% of the world's 'potential years of life lost' belong in the developing world, only $5 \%$ of the global research funds are devoted to studying the developing world's health problems." ${ }^{18}$

\section{Inhibiting Factors to Family Medicine Research in Developing Countries}

The constraints and problems encountered by primary care research workers would, in general, probably be similar to those experienced by their specialist colleagues in these countries or by primary care physicians in more developed countries.

General inhibiting factors are mainly related to the poor resources and structures within the health services (Table 1). Where war, civil unrest, corruption, and famine are rife, research is obviously not a priority. Funding precedence would also probably be given to studies that 


\section{Table 1. Some General Factors Inhibiting Family Medicine Research in Developing Countries}

Poor health care infrastructure-materials, manpower, political will

Limited financial resources-government priorities lie elsewhere in education, defence, general health care delivery, or debt repayment

Poor training in research methods, epidemiology and statistics in general medical training

Little incentive for a busy practitioner, overwhelmed by the system

Reluctance of international journals to publish papers from developing world $^{9}$

Research is not a priority of health system

Employment systems where only service is rewarded

Adapted from Horton R. North and South: bridging the information gap. Lancet. 2000;355:2231-2236.

\section{Table 2. Personal Factors That Limit Output of Research in Family Medicine}

No defined practice population, with mobile populations

Limitation or absence of reliable and comprehensive address lists to recruit participant physicians

Overworked physicians in primary care with limited time for research No protected time for research or writing

Limited or no access to research funds and grants, with inexperience in the grant application process

Limited exposure to "culture of research"

Lack of peer group in many countries to discuss, stimulate, or criticize work

Limited research expertise of individual physician, and little access to training in research methodology, epidemiology, and statistics

Limited support and supervision-supervisors are often at a distance because of sparse distribution of health personnel and often are insufficiently trained themselves

Prospect of rejection of developing world papers by international journals is inhibiting factor to a culture of research ${ }^{9}$

Poor or limited writing skills

address the major burdens of disease, such as malnutrition, human immunodeficiency virus (HIV) infection and acquired immunodeficiency disease syndrome (AIDS), and tuberculosis, rather than concerns related to patients' waiting times and person-centered consultations! Physicians who are faced with long queues of the desperately ill will also not be willing to give up time to what they may perceive as a waste of effort and energy. Their experience of previous research "leading to nothing" further entrenches their cynicism. In some situations physicians are reluctant to get involved in projects for fear that the findings could work against them.

We have had the experience of encountering such responses as, "Do not improve things-we will be flooded out even more," when suggesting studies and interventions aimed at improving the services and levels of care. Improving services and implementing evidence-based practice seem to be irrelevant when health systems are in disarray.

Corruption and political agendas sometimes militate against implementation of relevant health care despite meaningful and appropriate research, as evidenced by the recent reluctance of ill-advised South African authorities to implement antiretroviral therapy to manage the HIV/AIDS pandemic. The politicians and policies succumbed to the influence of dissident drug critics despite overwhelming evidence to the contrary. ${ }^{10}$

Apart from the general factors listed above, there are many personal considerations that can influence the output of research in some circumstances. These are summarized in Table 2. In many instances, though, researchers who work daily under the constraints of the health system are able to produce excellent studies despite these constraints.

\section{Ethical Considerations of Primary Care Research}

The peoples of developing countries are particularly vulnerable to exploitation by researchers. ${ }^{11}$ They may be insufficiently sophisticated to realize the implications of their involvement in the face of focused and perhaps free clinical care. Funding of research is sometimes based more on the needs of the funding agencies rather than relevant research based on the needs of these communities. Organizations such as the Welcome Trust have made considerable strides to reverse this trend. ${ }^{12}$ The Nuffield Council on Bioethics recommends that the development of local expertise in the provision of health care and in ethical health care research should be an integral component of any research proposal. ${ }^{13}$

Researchers should also be cognizant of the implications of the Declaration of Helsinki, particularly clause 29, which states that new treatments should be tested against the best current treatment rather than placebo. This clause was formulated in response to criticism related to the testing of antiviral agents in vertical transmission of HIV using placebo for the control group. ${ }^{14,15}$ This practice has been of particular concern to communities that have been used as cheap and ready subjects for drug research, usually before registration of the drug in the developed countries. Clause 15, on the other hand, limits medical research to supervision by clinically competent medical persons, which is an unfortunate limitation, because broader health research agendas in countries with poor resources may be led by epidemiologists, economists, and social scientists rather than physicians. ${ }^{16}$

A major consideration when conducting research in developing countries is that of informed consent. Formal assessment of research participants' comprehension of the content of consent forms should be considered a routine step in the informed consent process in less developed countries. ${ }^{17}$ In family medicine, research often involves highly personal disclosures by patients and exploration of intimate secrets. Obviously studies on the effects and implications of rape, sexual abuse, 
and HIV infections have major ethical implications, and the physician should always be aware of the power and influence that a professional health worker can have in such an interaction. ${ }^{18}$

\section{STRATEGIES TO DEVELOP AND STIMULATE FAMILY MEDICINE RESEARCH IN DEVEL- OPING COUNTRIES. \\ Increasing Capacity}

Because those in academia do most of the family medicine research in less developed countries, it would seem logical that capacity should be built by establishing more departments of family medicine. Regretfully the political will and finances are often lacking, and until authorities and decision makers are convinced by observing the benefits of relevant, high-quality research from the discipline, the priority for establishing departments may not be realized. Other strategies must be used to increase capacity.

Many family physicians in developing countries have not been exposed to research training, nor have they had the benefit of role models or mentors in research methods. With training in critical reading, however, they can be more adept at applying the findings of relevant studies. There are excellent courses available on the Internet for this purpose. ${ }^{19}$ Better links between clinical audit, continuing education, and research and development also need to be encouraged.

Involving physicians in ambulatory research networks has also proved to be successful. Initially these physicians partake as providers of data, but later they become actively involved in protocol development, reports, and publications. ${ }^{20}$

\section{Research Partnerships}

Partnerships among physicians and locally based research groupings would obviously be ideal for developing research expertise. Sentinel practice research networks have been successful in this regard, ${ }^{21}$ but they are limited in their distribution.

The International Clinical Epidemiology Network (INCLEN) is a network dedicated to improving the quality of health research in the developing world through institutional capacity building for evidence-based medicine. Clinician members of the trust participate in meaningful research development in developing countries. ${ }^{22}$ Organizations of family physicians in these countries may be well advised to contact them for assistance.

Strategies for building research capacity and to stimulate studies that will underpin health policy with sound evidence are a particular challenge to partners and research communities in developing countries. There are encouraging projects of applied research in Africa, Asia, and Latin America by programs that provide good training and support for local scientists and promote uptake of research results by end users in government, nongovernmental organizations, and other sectors. ${ }^{23}$

Partnerships, however, should be based on internationally acceptable codes of behavior. Costello and Zumla ${ }^{24}$ have articulated an excellent summary of principles of research partnership in developing countries. The Swiss Commission for Research Partnership with Developing Countries has also developed a useful checklist to evaluate research partnerships. ${ }^{25}$

\section{Access to Resources}

Access to resources for research, as well as research findings, is essential for any meaningful program. Many journals and other publications have become available for free on the Internet and in printed format for readers in developing countries. Initiatives such as that by the British Medical Journal to offer free international online access should be applauded. The lack of availability of hardware, poor Internet connections, and limited computer literacy do not aid those who most need the information. In Africa, of a population of 700 million, fewer than 1 million had Internet access in 1998 ; and of those, $80 \%$ were in South Africa. Of the remaining 20\%, only 1 in 5,000 had access (compared with 1 in 6 in the United States and Europe). ${ }^{26,27}$

For those writing grant proposals and protocols, the European Union funds a Web site called Scientists for Health and Research for Development (SHARED), listing potential donors, ongoing projects, and resources available to researchers in developing countries. ${ }^{28}$

\section{CHALLENGES FOR WONCA}

Whereas there are obviously numerous strategies to increase the output of family medicine research in developing countries, our particular emphasis in this article is to explore Wonca's possible facilitative role because of its international representation of individuals and member organizations. The following are some suggestions for collaborative action with its members:

1. Wonca is ideally positioned though its research committee to develop a resource center and clearinghouse of appropriate and applicable family medicine research internationally, including those studies from developing countries.

2. Wonca has recently established a new category of academic membership. This category enables academic departments of family medicine to contribute to development by forming networks and research groupings. Such members could assist by establishing research training and development programs in countries with limited expertise. 
3. Wonca intends to establish Web-based educational programs. Research training programs linked to a diploma qualification could be initiated. This service could build research capacity internationally.

4. Wonca could facilitate international and regional research collaboration initiatives to enhance expertise for meaningful and appropriate research. Such projects could influence health care planners to establish and support further academic initiatives in family medicine in deprived countries. Linkage through dedicated e-mail lists and other technologies is to be encouraged

5. Wonca could lobby and assist in drafting grant applications to international funding agencies. Ideally, grant applications should include funding for building capacity in research methods and execution.

6. Wonca should foster international research fellowships, student electives, and clerkships to encourage capacity building. This activity could be complemented by international development programs in which academics from more developed countries would assist in less developed regions. This assistance could include twinning initiatives between institutions and between member organizations of Wonca.

7. Wonca should encourage an international network of research initiatives, primary care research networks, centers of excellence, and individual researchers.

8. Together with its member organizations, Wonca should draft international ethical guidelines for research in family medicine.

9. Wonca should publish international consensus statements on education, research, and patient outcomes related to the effectiveness of family medicine programs in communities. These statements should be especially distributed in those countries where the discipline is not well known or accepted. Wonca and its member organizations would thus be political advocates for family medicine activities.

10. Member organizations should be encouraged to create a culture of audit by family physicians as a nursery to trigger more complicated research.

\section{CONCLUSION}

Family medicine research in developing countries requires further active international encouragement from within the discipline. Wonca, we believe, has a major role to play in achieving this end.

To read or post commentaries in response to this article, see it online at http://www.annfammed.org/cgi/content/full/2/suppl_2/S55.

Key words: Family medicine; research; developing countries

A version of this paper was presented at the Wonca Research Conference, Kingston, Ontario, Canada, March 8-11, 2003.

\section{References}

1. Sparks BLW. Report to Wonca World Council: Survey of Member Organisations of World Organisation of Family Doctors. South Africa: Alpine Heath; 2000.

2. Garner P, Kale R, Dickson R, Dans T, Salinas R. Implementing research findings in developing countries. BMJ. 1998;317:531-535.

3. Haines A, Donald A. Making better use of research findings. BMJ. 1998;317:72-75.

4. World Health Organization. The World Health Report 2001. Geneva: WHO; 2001.

5. Isaakidis P, Swingler GH, Pienaar E, Volmink J, loannina JPA. Relation between burden of disease and randomised evidence in subSaharan Africa: survey of research. BMJ. 2002;324:702.

6. Orne-Gliemann J, Perez F, Leroy V, Newell ML, Coutsoudis A, Coovadia $\mathrm{H}$. Improving child health: the role of research. BMJ. 2002;323: 1444-1447.

7. Page J, Heller RF, Kinlay S, et al. Attitudes of developing world physicians to where medical research is performed and reported. BMC Public Health. 2003;3:6.

8. Commission on Health Research for Development. Health Research. Essential Link to Equity in Development. Oxford: Oxford University Press; 1990.

9. Horton R. North and South: bridging the information gap. Lancet. 2000;355:2231-2236.

10. Cherry M. AZT critics "swayed South African President". Nature. 1999;402:225.

11. Schuklenk U. Protecting the vulnerable: testing times for clinical research ethics. Soc Sci Med. 2000;51:969-977.

12. Hargreave S. Wellcome Trust promotes ethical research in developing world. BMJ. 2002;325:986.

13. Nuffield Council on Bioethics. Report: The Ethics Of Research Related To Healthcare In Developing Countries. London: Nuffield Council on Bioethics; 2002.

14. World Medical Association. Declaration of Helsinki. Recommendations guiding physicians in biomedical research involving human subjects. JAMA. 1997;277:925-926.

15. Schuklenk U, Chokevivat V, delRio C, Gbadegesin S, Magis C. AIDS: ethical issues in the developing world. In: Kuhse $H$, Singer $P$, eds. A Companion to Bioethics. Oxford: Blackwell; 1998:355-365.

16. Tollman SM. Fair partnerships support ethical research. BMJ. 2001;323:1417-1423

17. Fritzgerald DW, Marotte C, Verdier RI, Johnson WD Jr, Pape JW. Comprehension during informed consent in a less-developed country. Lancet. 2002;1301-1302.

18. Sparks BLW. Micro-ethics of the consultation. CME (SAMJ). 1998;16: 846-847.

19. Greenhalg T. How to read a paper: a compilation. BMJ. 1997; BMJ.com How to read a paper. Available at: http://bmj/ bmjjournals.com/collections/read.shtml.

20. International Federation of Primary Care Research Networks. Available at: http://www.communities.msn.com/IFPCRN.

21. Pather MK. SASPREN - South African Sentinel Practitioner Research Network - Family Practitioner Primary Health Care Surveillance Project. Report for 2000/2001. Cape Town: South Africa Academy of Family Practice/Primary Care; 2002.

22. INCLEN Health Trust. Available at: http://www.inclentrust.org.

23. Sitthi-amorn C, Somrongthong R. Strengthening health research capacity in developing countries : a critical element for achieving health equity. BMJ. 2000;321:813-817.

24. Costello A, Zumla A. Moving to research partnerships in developing countries. BMJ. 2000;321:827-829.

25. Swiss Commission for Research Partnership with Developing Countries. Guidelines for Research in Partnership with Developing Countries. Bern: The Commission; 1998.

26. Lown B, Bukachi F, Xavier R. Health information in the developing world. Lancet. 1998;351(suppl II):11-19.

27. Tan-Torres Edejer T. Disseminating health information in developing countries: the role of the internet. BMJ. 2000;321:797-800.

28. Scientists for Health and Research for Development (SHARED). Available at: http://shared-global.collexis.net/main.asp. 